Article

\title{
Effect of pH Variations on the Yield Stress of Calcium Bentonite Slurry Treated with pH-Responsive Polymer
}

\author{
Hyunwook Choo ${ }^{1}$, Youngmin Choi ${ }^{2}$, Woojin Lee ${ }^{3}$ and Changho Lee ${ }^{4, *(\mathbb{D}}$ \\ Department of Civil Engineering, Kyung Hee University, Yongin 17104, Korea; choohw@khu.ac.kr \\ Infra Engineering Team 2, SK Engineering \& Construction Co., Ltd., Seoul 04534, Korea; choiym@sk.com \\ 3 School of Civil, Environmental, and Architectural Engineering, Korea University, Seoul 02841, Korea; \\ woojin@korea.ac.kr \\ 4 Department of Civil Engineering, Chonnam National University, Gwangju 61186, Korea \\ * Correspondence: changho@jnu.ac.kr
}

Received: 28 April 2020; Accepted: 30 May 2020; Published: 1 June 2020

check for updates

\begin{abstract}
The $\mathrm{pH}$-responsive polymers, such as polyacrylamide (PAM), show distinct conformational states according to the $\mathrm{pH}$ of their environmental groundwater. Therefore, the interactions between clay-polymer and polymer-water molecules, which determine the yield stress of bentonite-polymer composites, can be affected by the $\mathrm{pH}$ of groundwater. This study aims to evaluate the effect of $\mathrm{pH}$ variation on the yield stress of calcium bentonite treated with PAM. The yield stresses $\left(\tau_{y}\right)$ of untreated and PAM treated clays were measured with varying volume fractions of solid (VF $=10-23 \%)$ and under varying $\mathrm{pH}$ conditions ( $\mathrm{pH}=7.6-9.6)$. In addition, the zeta potential was measured for both untreated and treated clays to figure out the change in the surface charge of the mineral surface due to PAM treatment. The results of this study demonstrate that $\tau_{y}$ for treated clay is higher than that for untreated clay at a given VF, because van der Walls attraction dominates electrostatic repulsion in the case of treated clay. Due to the change in conformational states of PAM and the consequent change in surface charge that comes with varying $\mathrm{pH}$, the $\mathrm{pH}$-dependent change in $\tau_{y}$ of treated clay is significantly different from that of untreated clay.
\end{abstract}

Keywords: polyacrylamide; calcium bentonite; yield stress; $\mathrm{pH}$; zeta potential

\section{Introduction}

Bentonite slurry has been widely used for various engineering purposes, such as slurry walls, grouts, and boring fluids, due to its low hydraulic conductivity and high swelling characteristics. Although sodium bentonite is widely used due to its superior engineering performance, natural deposits of calcium bentonite are globally more common than those of sodium bentonite [1,2]. Due to the calcium ion, calcium bentonites show relatively poor engineering performance compared to sodium bentonites [1,3-7]. Therefore, to satisfy engineering requirements, a low-quality calcium bentonite is typically admixed with additives, such as phosphate [8-10], sodium carbonate [11], and polymer [3,12].

When the bentonite slurry is employed as a grout material, its rheological properties, such as yield stress and viscosity, are very important. Especially, yield stress is the key parameter determining the injectability of grout into the ground and also determining resistivity against erosion by groundwater flow after installing the grout [13-15]. Note that yield stress is defined as "the stress above which the material flows like a viscous fluid" [16]. It is well known that the yield stress of bentonite slurry can be affected by a number of parameters, including the clay concentration, type of bentonite, molar ratio of $\mathrm{Na} / \mathrm{Ca}$, microstructure, electrolyte concentration, and $\mathrm{pH}[9,11,17-20]$. 
If bentonite slurry is admixed with a polymer, the factors influencing yield stress become more complex due to the additional interactions between clay-polymer and polymer-pore fluid [3]. Previous studies on clay-polymer composite have focused on the type of polymer and polymer concentration in order to explore interactions between clay-polymer and polymer-water molecules [21-24]. In contrast, studies evaluating the effect of $\mathrm{pH}$ on the yield stress of clay-polymer composite are limited, although the interactions between clay-polymer and polymer-water molecules can be changed by the $\mathrm{pH}$ of groundwater. Especially, $\mathrm{pH}$-responsive polymers, such as polyacrylamide (PAM), show distinct conformational states according to the $\mathrm{pH}$ of environmental groundwater. Therefore, to estimate the effect of $\mathrm{pH}$ on the yield stress of clay-polymer composite, in this study, a calcium bentonite was treated with a nonionic PAM, and the yield stresses of both untreated and treated clay were measured according to the various clay contents and $\mathrm{pH}$ conditions. In addition, zeta potential values of untreated and treated clay were measured to gain an insight into the surface charge of the mineral surface.

\section{Materials and Methods}

\subsection{Materials}

\subsubsection{Bentonite}

In this study, a calcium bentonite produced by Donghae Chemicals Industrial (Korea) was used as a base material. The clay was sieved through a No. 200 sieve to minimize large-sized impurities. The mineralogy of the bentonite was measured using an X-ray diffractometer (XPERT MPD, Philips, Almelo, the Netherlands, maximumradiation; $3 \mathrm{~kW}$ ) as shown in Figure 1. The angle scanned was $2^{\circ}-42^{\circ}(2 \theta)$ at a rate of $0.04^{\circ} / \mathrm{s}(2 \theta / \mathrm{s})$. The main clay mineral was revealed to be a montmorillonite. The chemical composition of the bentonite (Table 1) was measured using X-ray fluorescence (XRF) spectrometry (Philips, Almelo, the Netherlands, PW2404, $60 \mathrm{kV} ; 125 \mathrm{~mA}$; maximum of $4 \mathrm{~kW}$ for an $\mathrm{X}$-ray tube with a Rh anode). Since the $\mathrm{Na}^{+} / \mathrm{Ca}^{2+}$ ratio (0.53) was smaller than 1 , the bentonite used in this study can be classified as a calcium bentonite. The index properties of the tested calcium bentonite are given in Table 2 . The specific gravity $\left(G_{s}\right)$ was determined to be 2.51 by water pycnometer method [25]. The plastic limit (PL) was determined to be $35.83 \%$ by the traditional thread-rolling method [26], and the liquid limit (LL) was determined to be $86.76 \%$ by the fall cone method [27]. Therefore, the tested calcium bentonite was classified as a clay with high plasticity $(\mathrm{CH})$, in accordance with the Unified Soil Classification System [28]. The specific surface area $\left(S_{a}\right)$ was $260.56 \mathrm{~m}^{2} / \mathrm{g}$ according to the methylene blue spot test [29], and the $\mathrm{pH}$ value was 8.48 for $2 \%$ solid contents. The cation exchange capacity (CEC) was measured to be $89.65 \mathrm{meq} / 100 \mathrm{~g}$ by the ammonium acetate method [30].

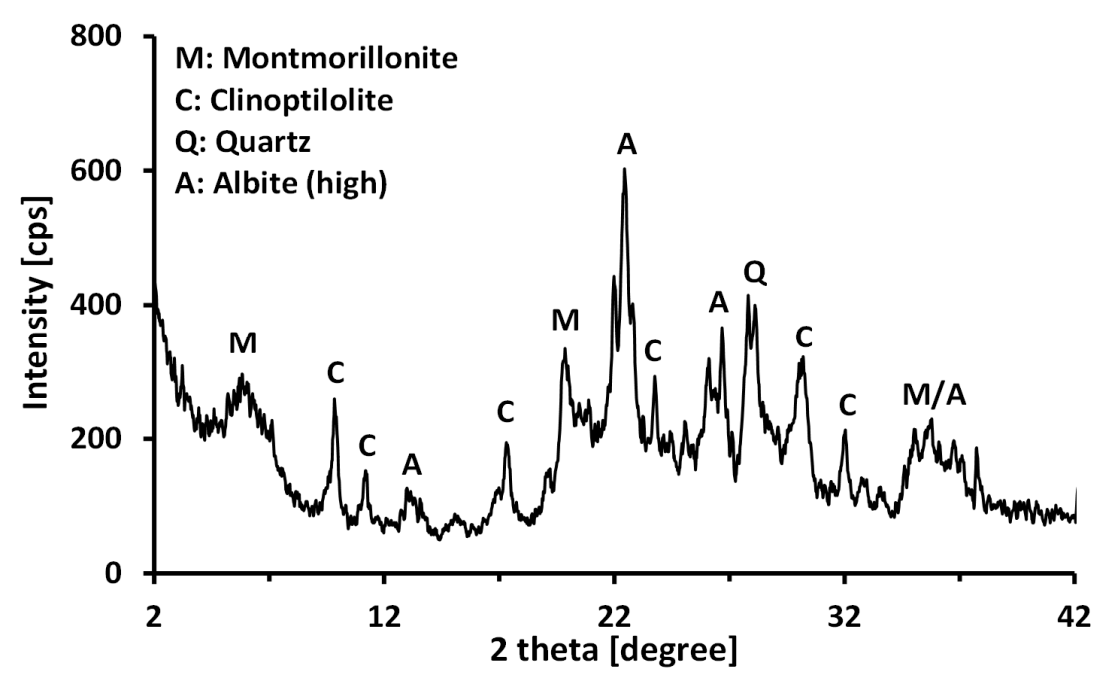

Figure 1. X-ray diffraction (XRD) pattern of the calcium bentonite used in this study. 
Table 1. Chemical composition of the calcium bentonite.

\begin{tabular}{cccccccccccc}
\hline Component & $\mathrm{SiO}_{2}$ & $\mathrm{Al}_{2} \mathrm{O}_{3}$ & $\mathrm{Fe}_{2} \mathrm{O}_{3}{ }^{\mathrm{a}}$ & $\mathrm{CaO}$ & $\mathrm{K}_{2} \mathrm{O}$ & $\mathbf{M g O}$ & $\mathrm{Na}_{2} \mathrm{O}$ & $\mathrm{TiO}_{2}$ & $\mathbf{M n O}$ & $\mathbf{P}_{2} \mathrm{O}_{5}$ & $\mathbf{L O I}^{\mathbf{b}}$ \\
\hline $\begin{array}{c}\text { wt.\% } \\
\text { composition }\end{array}$ & 65.06 & 15.43 & 3.94 & 2.33 & 2.06 & 1.28 & 1.24 & 0.52 & 0.11 & 0.09 & 6.77 \\
\hline \multicolumn{8}{c}{${ }^{\mathrm{a}} \mathrm{Fe}_{2} \mathrm{O}_{3}=$ total Fe; ${ }^{\mathrm{b}}$ Loss of ignition }
\end{tabular}

Table 2. Index properties of the tested clays.

\begin{tabular}{cccccccc}
\hline Sample & $G_{s}$ & LL [\%] & PL [\%] & $S_{a}\left[\mathbf{m}^{2} / \mathbf{g}\right]$ & $\mathbf{p H}$ & $\mathrm{CEC}[\mathrm{cmol} / \mathbf{k g}]$ & USCS \\
\hline Untreated & 2.51 & 86.76 & 35.83 & 260.56 & 8.48 & 89.65 & $\mathrm{CH}$ \\
Treated & 2.47 & 121.53 & 38.10 & 263.62 & 8.46 & 89.21 & $\mathrm{CH}$ \\
\hline
\end{tabular}

\subsubsection{Polyacrylamide (PAM)}

In this study, a nonionic PAM (Yangfloc N-100P, OCI-SNF, Seoul, Korea) was chosen to create a PAM treated clay because of its large deformable capacity with varying $\mathrm{pH}$ [31]. As shown in Figure 2a, the nonionic PAM contracts at a low $\mathrm{pH}$ and extends at high $\mathrm{pH}$. Therefore, it was expected that the clay-PAM composite can have $\mathrm{pH}$-dependent engineering properties. The molecular weight and charge density of the PAM were $8.5 \times 10^{6} \mathrm{~g} / \mathrm{mol}$ and $-0.56-1.23 \mathrm{meq} / 100 \mathrm{~g}$ (data from the manufacturer), respectively. Interaction between PAM molecules and clay particles can be achieved by: (1) the carbonyl oxygen $(-\mathrm{C}=\mathrm{O})$ of PAM molecules can form hydrogen bonds between PAM and the clay surface (Figure 2b); and (2) ion-dipole interactions can occur between the polar group $\left(-\mathrm{NH}_{2}\right)$ of PAM molecules and the interlayer cations of clay (Figure 2b) [32]. It is through these reactions that the clay-PAM composite is formed.

(a)

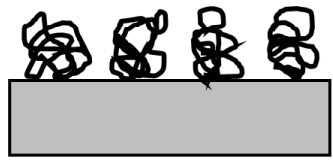

$\mathbf{p H}=\mathbf{2 . 3}$

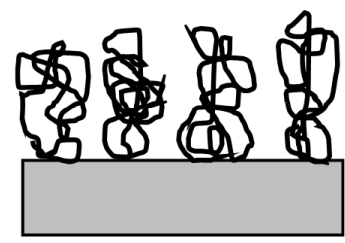

$\mathrm{pH}=6.4$

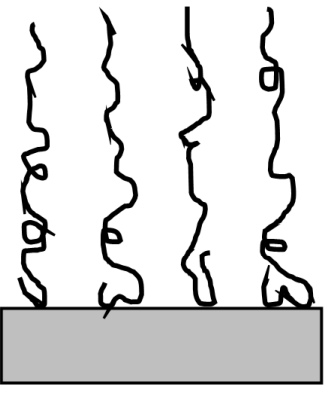

$\mathrm{pH}=\mathbf{1 0 . 9 5}$

(b)

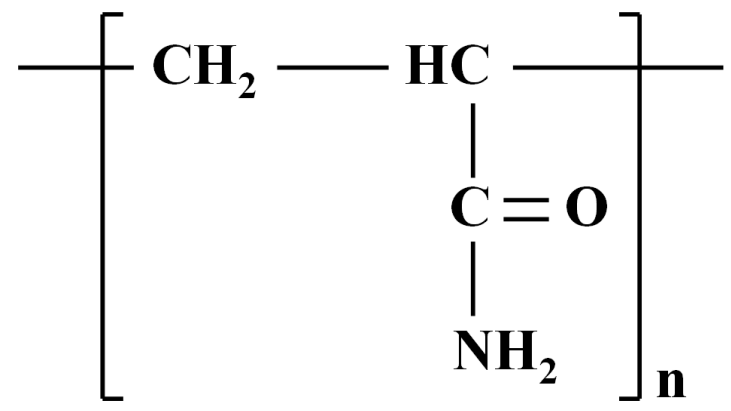

Figure 2. Nonionic polyacrylamide (PAM): (a) schematic drawing of the conformational state of adsorbed PAM at different pH conditions (after [31]) and (b) chemical structure of PAM (after [33]). 


\subsection{Preparation of PAM Treated Clay}

The PAM treated clay was prepared following the method suggested by [34]. $300 \mathrm{~g}$ of the dried clay was mechanically blended with $6 \mathrm{~L}$ of deionized water for $24 \mathrm{~h}$ to ensure complete dispersion. $1 \mathrm{~L}$ of the nonionic PAM solution was then poured into the slurry. The concentration of PAM in the slurry was $1.88 \mathrm{~g} / \mathrm{L}$ ( $131.6 \mathrm{mg}$ of the PAM for $100 \mathrm{~g}$ of the clay). The concentration of $1.88 \mathrm{~g} / \mathrm{L}$ was chosen, because the swelling index of the PAM treated clay, determined by [35], reaches a maximum value $(\approx 7.4 \mathrm{~mL} / 2 \mathrm{~g})$ at the concentration of $1.88 \mathrm{~g} / \mathrm{L}$. After continuous stirring for $24 \mathrm{~h}$, the slurry was allowed to settle down for $1 \mathrm{~h}$. Any supernatant liquid was drained out, then the slurry was dried in an oven at $110^{\circ} \mathrm{C}$ for one day. Prior to performing any experiments, the dried clay was ground with a mortar and pestle, then sieved through a No. 200 sieve. The index properties of the PAM treated clay are tabulated in Table 2.

\subsection{Yield Stress Measurement}

Yield stress of the slurry specimen was measured using a rheometer (Brookfield, RST-SST, Middleborough, MA, USA) with a 4 blades vane spindle (VT-80-70; height of vane $=80 \mathrm{~mm}$ and width of a vane blade $=35 \mathrm{~mm}$ ). The $1.1 \mathrm{~L}$ slurry specimen was prepared in a $1.2 \mathrm{~L}$ tall-form beaker (inner diameter $93 \mathrm{~mm}$ ), then the slurry was rested for $24 \mathrm{~h}$ to complete the hydration reaction. After the equilibration time, the slurry was thoroughly mixed for $1 \mathrm{~min}$, then the yield stress was measured at the spindle rotational speed of $0.5 \mathrm{rpm}$. After the yield stress measurement, the $\mathrm{pH}$ of the specimen was measured by a pH strip (Advantec, Dublin, CA, USA), and the supernatant liquid was extracted by centrifuging from a small sample to measure the electrical conductivity of pore water in the specimen using a conductivity meter (Fisher Scientific, XL50, Pittsburgh, PA, USA).

\section{Results and Discussions}

\subsection{Effect of PAM Treatment on Stress-Time Curve}

Figure 3 shows typical stress-time curves of untreated and treated clays at respective water contents ( $w=$ weight of water/weight of solid) of $218 \%$ and $263 \%$. Figure 3 a shows a typical stress-time curve for the untreated sample: shear stress linearly increases with time initially before reaching a maximum value, it then decreases to a quasi-constant value. Previous studies have defined the peak stress in a stress-time curve as the yield stress $\left(\tau_{y}\right)$ [36-39]. However, for the PAM treated specimen, the peak stress was not observed in the stress-time curve under the tested solid contents and $\mathrm{pH}$ conditions (Figure 3b). [40] also observed the absence of a peak stress for PAM treated kaolin clay in their results from a consolidated undrained triaxial test. Therefore, the $\tau_{y}$ of the treated clay was determined as the shear stress, at which the stress initiated the post-peak hardening behavior, as illustrated in Figure 3b. 
(a)

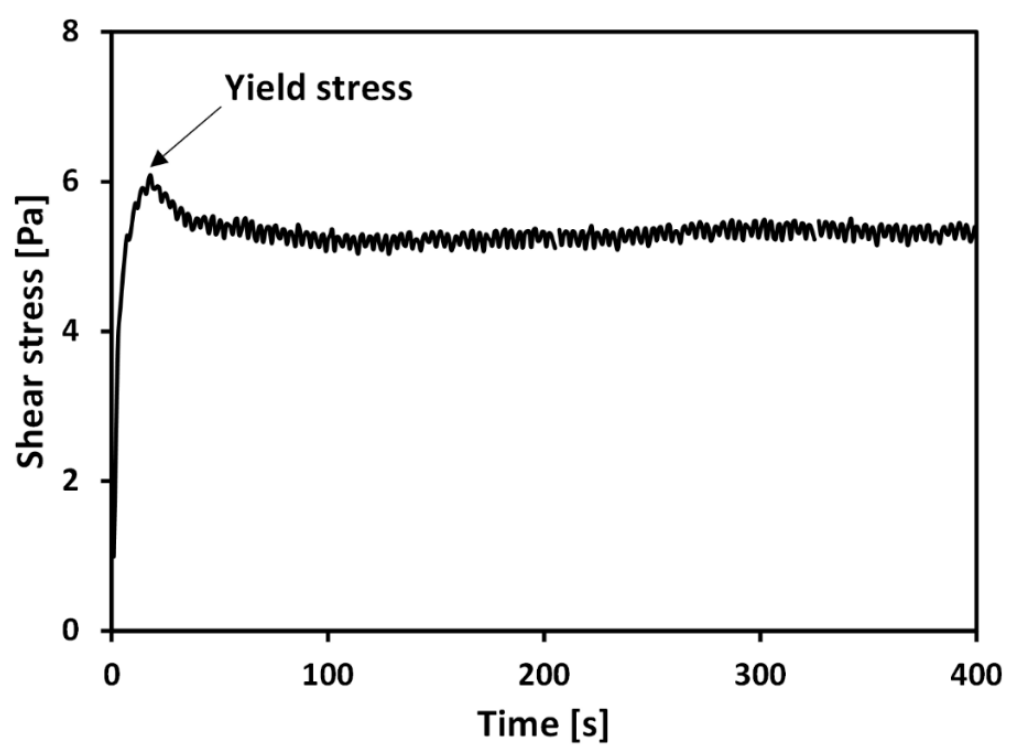

(b)

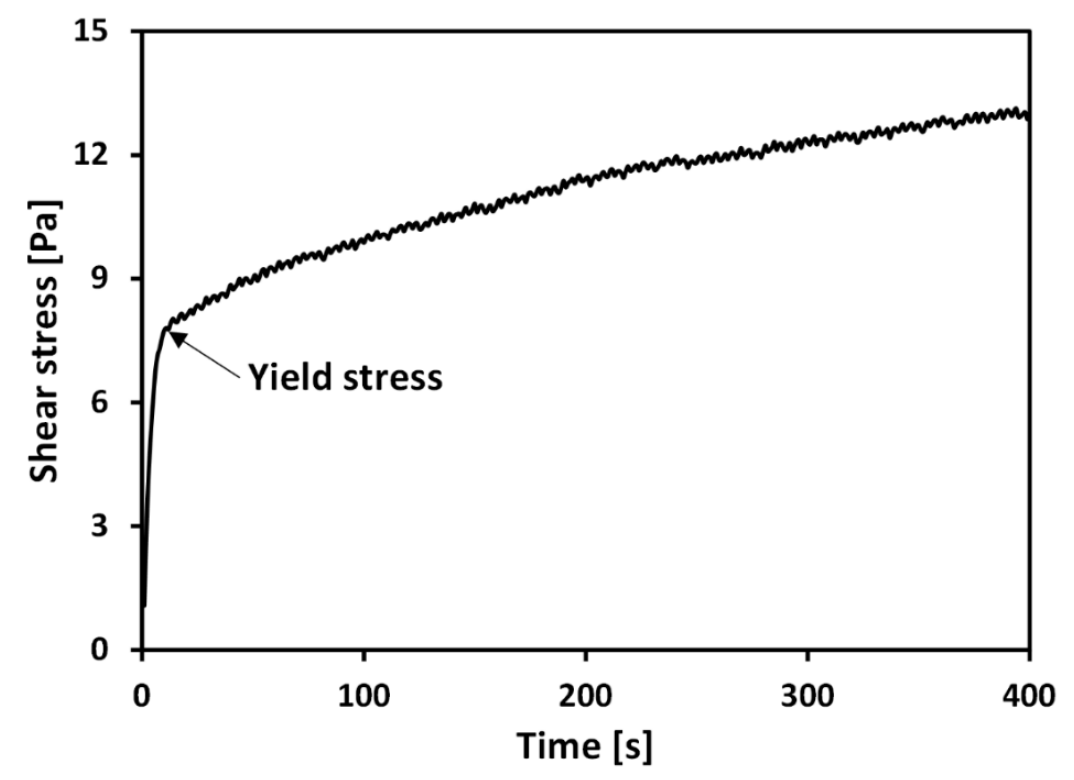

Figure 3. Typical stress-time curves of (a) untreated (water content $=218 \%$ ) and (b) treated (water content $=263 \%$ ) clays.

The difference in the stress-time profiles between the untreated and treated clays corresponds to differences in the microstructures of the slurries. In the case of the untreated clay slurry, an aggregated or dispersed structure developed due to the calcium ions [1,3,5]. As the untreated specimen is sheared by the vane, the aggregated/dispersed structure is destroyed at the peak shear strength, followed by a reduction in stress due to slips and rearrangements between clay particles. However, in the case of the treated clay slurry, the adsorbed PAM on the clay surface resulted from hydrogen bonds and ion-dipole interactions between PAM and the clay particles. However, in the case of the treated clay slurry, the adsorbed PAM on the clay surface, resulted from hydrogen bonds and ion-dipole interactions between PAM and the clay particles, can develop the molecular bridges between adjoining clay particles, known as polymer bridging [34,40-42]. This results in the prevention of slips and rearrangements between particles after reaching yield stress, and gives rise to the post-peak hardening behavior characteristic of PAM treated clay. 


\subsection{Effect of Solid Content on the Yield Stress}

Yield stress $\left(\tau_{y}\right)$ is significantly affected by the solid content of the sample $[9,43,44]$. To explore the effect of PAM treatment on the yield stress of the tested calcium bentonite, the yield stresses of untreated and treated clays with varying solid contents were measured. Figure 4 shows $\tau_{y}$ of untreated and treated clays as a function of volume fraction of solid (VF) at a $\mathrm{pH}$ of around 8.4, which is the natural $\mathrm{pH}$ without adding any $\mathrm{pH}$ adjusting agent, measured by a $\mathrm{pH}$ strip. Note the natural $\mathrm{pH}$ of pore fluids obtained by centrifuging samples was also determined to be 8.4-8.5, measured by a pH meter (Fisher Scientific, XL50, Pittsburgh, PA, USA). The VF was calculated according to:

$$
V F=\frac{V_{\text {solids }}}{V_{\text {total }}}=\frac{1}{\left(1+w \cdot G_{s}\right)}
$$

where $V_{\text {soilds }}$ is volume of solid, $V_{\text {total }}$ is total volume, $w$ is water content, and $G_{s}$ is specific gravity. As shown in Figure 4, $\tau_{y}$ for the treated clay was higher than that for the untreated clay at a given $V F$, reflecting the clear impact of PAM on the rheological behavior of the tested bentonite. It can also be observed in Figure 4, that $\tau_{y}$ of both untreated and treated clays exponentially increases with increasing $V F$; thus, $\tau_{y}$ of both clays are proportional to VF in a semi-logarithmic plot.

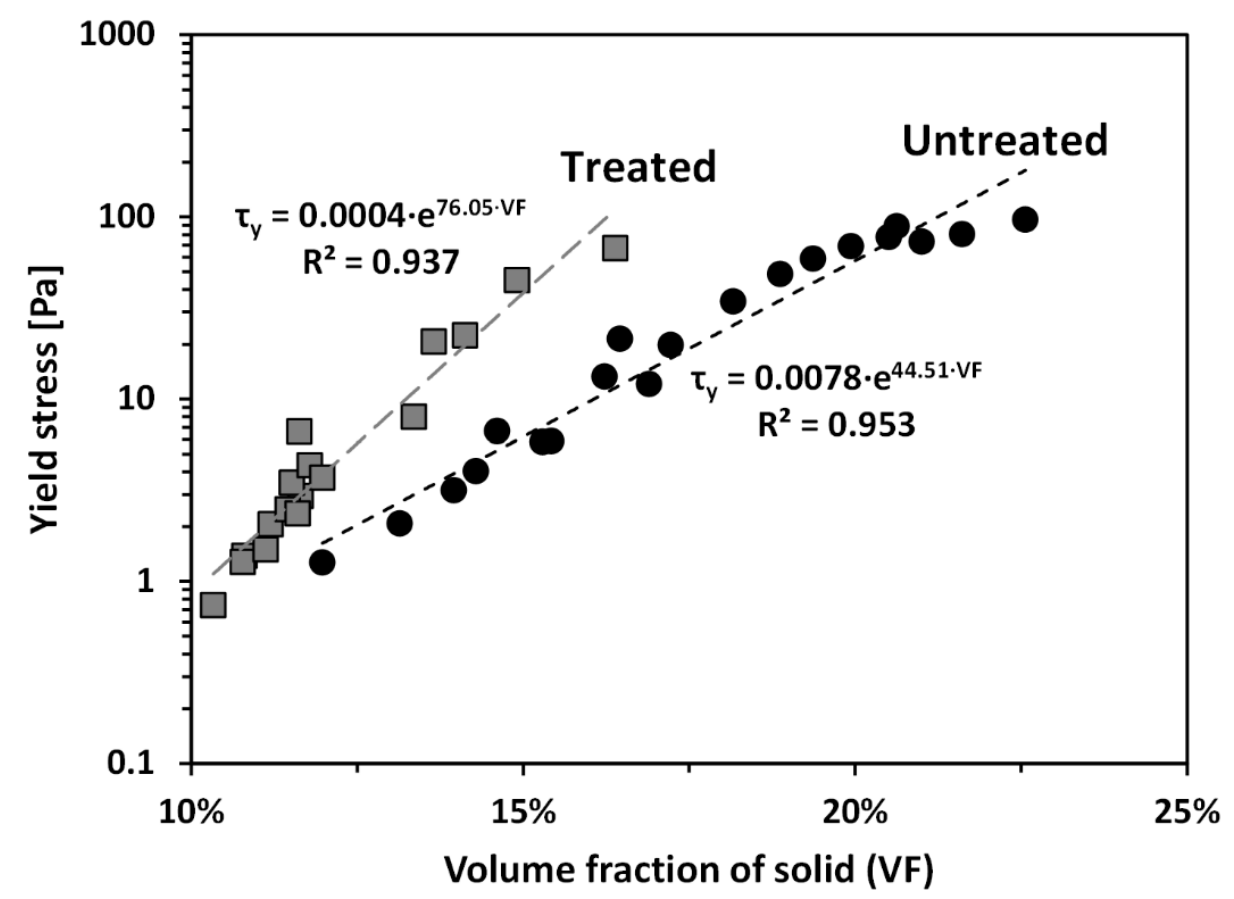

Figure 4. Yield stresses of untreated and treated clays as a function of volume fraction of solid $(V F)$.

The network structure of clay particles (i.e., the card-house structure, resulting from edge $(+) /$ face $(-)$ contacts; and the band-like structure, resulting from face $(-) /$ face $(-)$ contacts), which determines $\tau_{y}$ of clay slurry, is affected by surface charge of the clay particle surface [20]. As zeta potential gives an insight into the surface charge of a mineral surface, many previous studies have investigated the direct relationship between the zeta potential and yield stress of clay slurry $[9,45]$. Figure 5 shows the zeta potential $(\zeta)$ of the tested untreated and treated clays as a function of $\mathrm{pH}$, ranging from 2.8 to 11.8. At a $\mathrm{pH}$ of around 8.4, it can be observed in Figure 5 that the absolute $\zeta$ of treated clay is smaller than that of untreated clay, because the nonionic PAM adsorbed on the clay particle surface neutralizes the surface charge of clay particles [46]. In the case of treated clay, this results in the van der Walls attractive force overwhelming the electrostatic repulsive force, resulting from the diffuse double layer 
with counter-ions. Consequently, the treated clay can form the dense structure. Therefore, the yield stress of treated clay at a given solid content is greater than that of untreated clay.

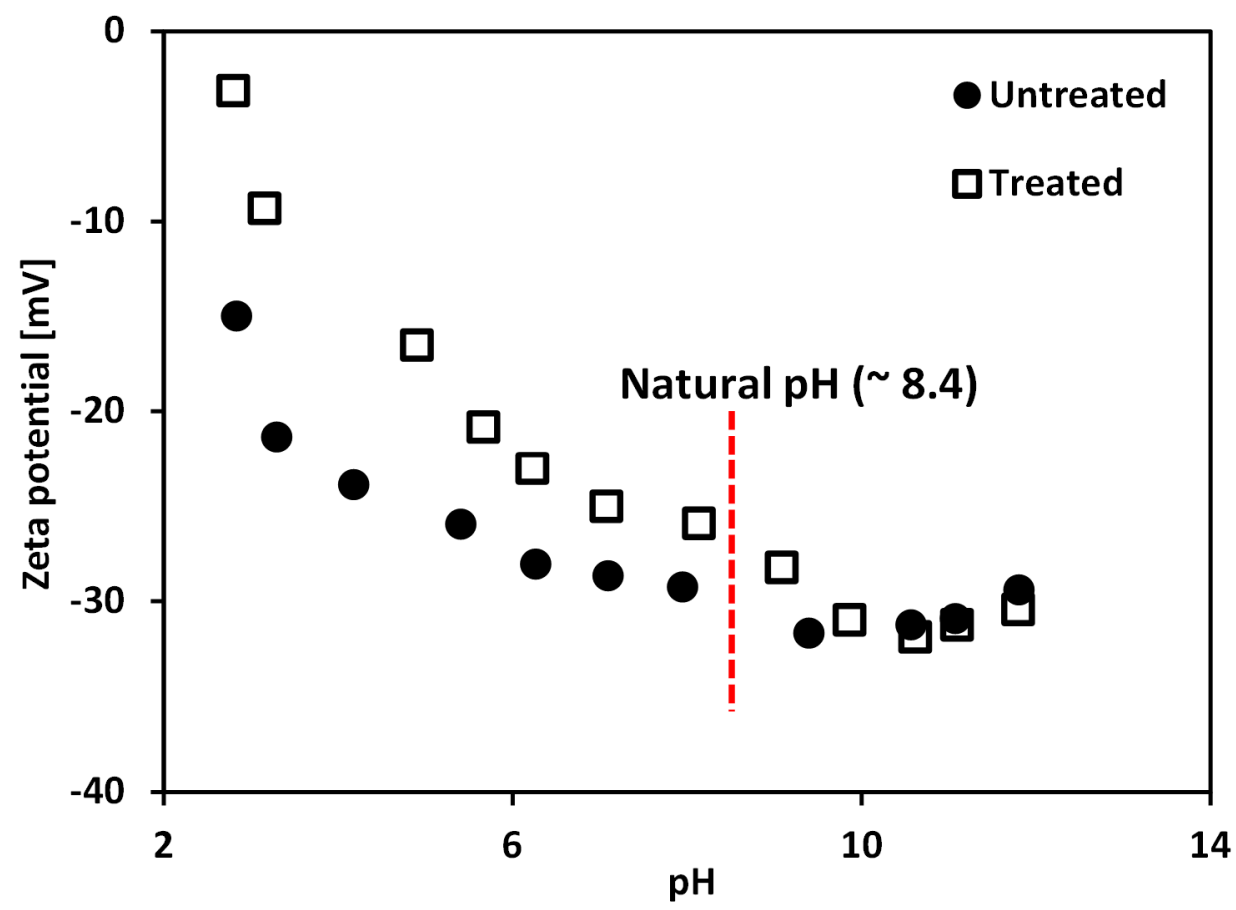

Figure 5. Variations of zeta potential of treated and untreated clays as a function of $\mathrm{pH}$. Note zeta potential was measured using zeta potential analyzer (Otsuka Electronics, ELSZ-1000, Osaka, Japan) with the sample of $0.6 \mathrm{~g}$ of dry soil dispersed in $1 \mathrm{~L}$ of $0.01 \mathrm{M} \mathrm{NaCl}$ solution.

Additionally, because the adsorbed PAM provides polymer bridging between particles $[34,40,41]$, the polymer bridging may act as flexible reinforcement and may provide additional shear resistance by increasing the internal kinematic constraints on soil particles. This explanation of the contribution of polymer bridging to the increase in $\tau_{y}$ can be further supported by comparing the slopes between $\tau_{y}$ and $V F$ of treated and untreated clays (Figure 4): the difference in $\tau_{y}$ between treated and untreated clays increases with $V F$, because the chance to form the polymer bridging between particles also increases.

\subsection{Effect of $\mathrm{pH}$ Variations on the Yield Stress}

Figure 6a shows variation of yield stress $\left(\tau_{y}\right)$ as a function of $\mathrm{pH}$ for the treated and untreated clays at volume fractions of solid $(V F)$, of $11.5 \%$ and $15.3 \%$, respectively. Note that the selected $V F$ values for the two tested materials are based on the similar $\tau_{y}$ at a $\mathrm{pH}$ of 8.4 (natural $\mathrm{pH}$ without adding $\mathrm{pH}$ adjusting agent), as shown in Figure 6a. Figure 6a clearly demonstrates that $\tau_{y}$ values of both untreated and treated clays increases as $\mathrm{pH}$ decreases. The microstructure of bentonite clay tends to form a flocculated structure (i.e., increasing edge (+)/face (-) interaction) with decreasing $\mathrm{pH}[18,20]$. As the strength of a flocculated structure is higher than that of a dispersed structure $[9,20,47]$, an increase in $\tau_{y}$ with decreasing $\mathrm{pH}$ is expected. In contrast, when the $\mathrm{pH}$ increases, the microstructure of bentonite clay tends to form a dispersed structure (i.e., increasing face (-)/face $(-)$ interaction), resulting in a decrease in $\tau_{y}$. 
(a)

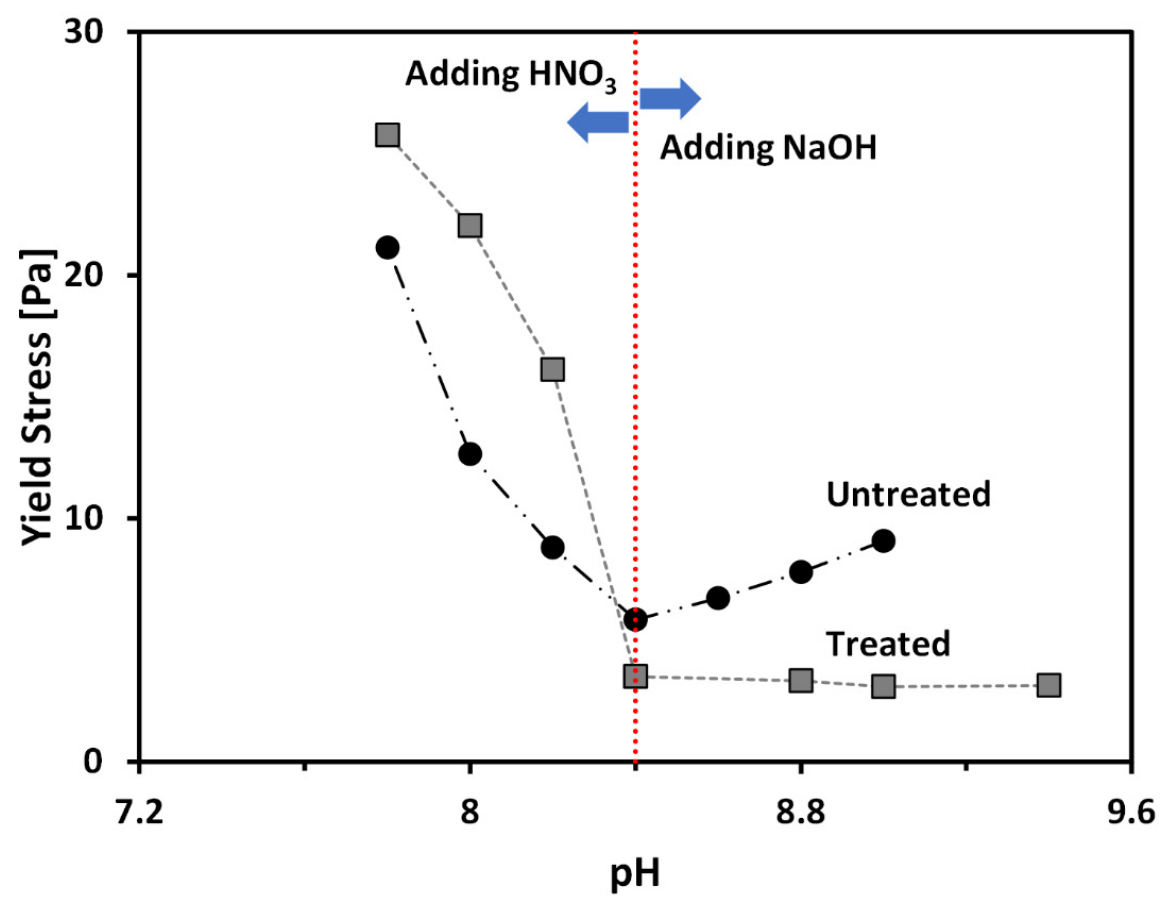

(b)

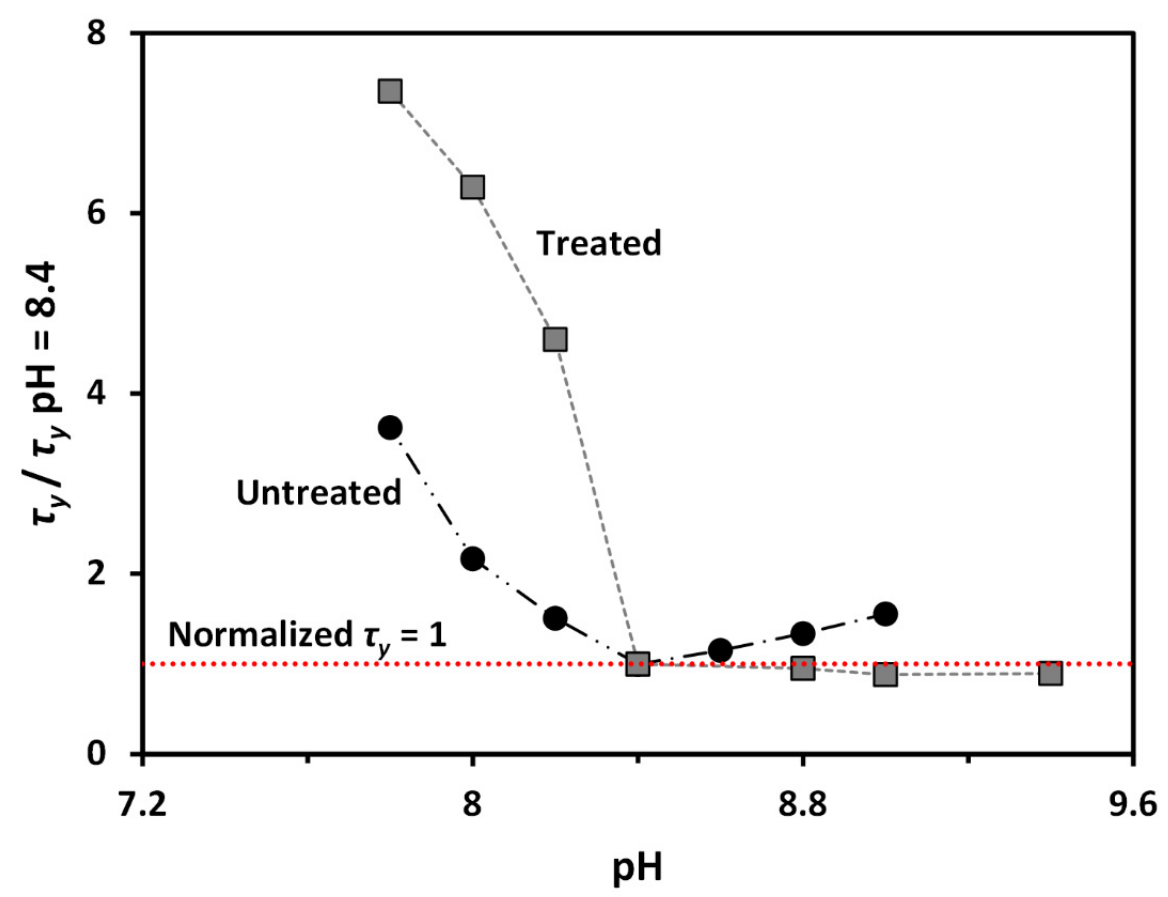

Figure 6. Effect of $\mathrm{pH}$ on the yield stress of treated and untreated clays: (a) variation of yield stress; and (b) variation of normalized yield stress (yield stress/yield stress at $\mathrm{pH}$ of 8.4).

The $\mathrm{pH}$ adjustment (i.e., either decreasing $\mathrm{pH}$ by addition of $\mathrm{HNO} 3$ or increasing $\mathrm{pH}$ by addition of $\mathrm{NaOH}$ ) accompanies an increase in the electrolyte concentration within pore fluid. This increase in the electrolyte concentration can lead to an increase in $\tau_{y}$ due to a reduction in repulsive force between clay particles $[7,20]$ and the consequent formation of a denser structure. Therefore, an increase in $\tau_{y}$ with changing $\mathrm{pH}$ can be accelerated in low $\mathrm{pH}$ conditions, due to the combined effects of $\mathrm{pH}$ 
and electrolyte concentration (Figure 6a). In contrast, the increase in $\tau_{y}$ with changing $\mathrm{pH}$ is very gradual or minimal in high $\mathrm{pH}$ conditions, due to the offset mechanism between the $\mathrm{pH}$ and electrolyte concentration (Figure 6a): an increase in $\mathrm{OH}^{-}$concentration leads to the expansion of the diffuse double layer and the consequent increase in repulsive force between particles; at the same time, high electrolyte concentration leads to a decrease in repulsive force.

In order to directly compare $\mathrm{pH}$-dependent changes in $\tau_{y}$ of untreated and treated clays, a normalized $\tau_{y}$, which is defined as the ratio between $\tau_{y}$ and $\tau_{y}$ at a $\mathrm{pH}$ of 8.4 (natural $\mathrm{pH}$ ), is plotted as a function of $\mathrm{pH}$ in Figure $6 \mathrm{~b}$. Figure $6 \mathrm{~b}$ demonstrates that as $\mathrm{pH}$ decreases from 8.4 to lower values, the treated clay shows a bigger increase of the normalized $\tau_{y}$ than untreated clay. In contrast, as the $\mathrm{pH}$ increases from 8.4 to higher values, the normalized $\tau_{y}$ shows very gradual increase in the case of untreated clay; while, the treated clay shows a very slight decrease in the normalized $\tau_{y}$. This difference in the $\mathrm{pH}$-dependent change of normalized $\tau_{y}$ for untreated and treated clays reflects that the varying conformational states of PAM with $\mathrm{pH}$ have a significant influence on $\tau_{y}$ of the tested calcium bentonite. As the PAM molecules contract with decreasing $\mathrm{pH}$ (Figure 2), the resulting microstructure of treated clay becomes denser than untreated clay because of the decreased repulsive force between clay particles, which resulted from the increased clay surface coverage by the highly coiled PAM. The increase in the difference between the zeta potential $(\zeta)$ values of untreated and treated clays with decreasing $\mathrm{pH}$ from 8.4 to lower values may support this explanation (Figure 5). Therefore, the bentonite treated with PAM shows a greater increase in yield stress with decreasing $\mathrm{pH}$ than untreated bentonite. In contrast, as the PAM molecules extend with increasing $\mathrm{pH}$ (Figure 2), the resulting microstructure of treated clay was in a loose (dispersed) state, due to the neutralization of the surface charge by the adsorbed PAM, and was reduced due to a decrease in the region of attached segments of polymer on the clay surface. The $\zeta$ values of treated clay approach those of untreated clay at high $\mathrm{pH}$ in Figure 5 and also supports this explanation. Furthermore, the net change in $\zeta$, when $\mathrm{pH}$ increases from $\mathrm{pH} 8.4$ to higher values of treated bentonite, is greater than that of untreated bentonite. Therefore, the treated clay may experience significant increases in repulsive forces between particles when changing $\mathrm{pH}$ from 8.4 to higher values. Consequently, it can be postulated that, in the case of treated clay, the increase in repulsive force due to the $\mathrm{pH}$ change is greater than the decrease in repulsive force due to the increase of electrolyte concentration. This results in the treated clay showing a slight decrease in yield stress when increasing $\mathrm{pH}$ from 8.4 to higher values; while, untreated clay shows a gradual increase in yield stress, as shown in Figure 6.

\section{Summary and Conclusions}

This study measured the yield stresses $\left(\tau_{y}\right)$ of untreated and PAM treated clays, with varying volume fractions of solid $(\mathrm{VF}=10-23 \%)$ and varying $\mathrm{pH}$ conditions $(\mathrm{pH}=7.6-9.6)$. The key findings of this study are:

(1) The peak stress was not observed in the stress-time curve of the treated bentonite, because the polymer bridging between clay particles can prevent slips and rearrangements between particles after reaching $\tau_{y}$.

(2) $\tau_{y}$ for the treated clay was higher than that for untreated clay at a given $V F$, because van der Walls attraction dominates electrostatic repulsion in the case of treated clay. In addition, polymer bridging may act as flexible reinforcement and may provide additional shear resistance, leading to increases in $\tau_{y}$ for the treated clay.

(3) An increase in $\tau_{y}$ with decreasing $\mathrm{pH}$ can be accelerated in low $\mathrm{pH}$ conditions due to the combined effects of $\mathrm{pH}$ (i.e., formation of flocculated structure) and electrolyte concentration (i.e., formation of dense structure).

(4) The varying conformational states of PAM with $\mathrm{pH}$ significantly influences the $\tau_{y}$ of tested calcium bentonite. Therefore, the treated clay shows greater increases in normalized $\tau_{y}$ than untreated clay as the $\mathrm{pH}$ decreases from 8.4 to lower values. 
Author Contributions: Conceptualization, W.L. and C.L.; methodology, Y.C. and W.L.; formal analysis, Y.C. and H.C.; investigation, Y.C. and C.L.; writing-original draft preparation, Y.C. and H.C.; writing-review and editing, H.C. and C.L. All authors have read and agreed to the published version of the manuscript.

Funding: This research was supported by the National Research Foundation of Korea (NRF) grant funded by the Korean government (NRF-2017R1C1B2004036 and NRF-2019R1C1C1005310).

Conflicts of Interest: The authors declare no conflict of interest.

\section{References}

1. Egloffstein, T. Natural bentonitesâ $€$ "influence of the ion exchange and partial desiccation on permeability and self-healing capacity of bentonites used in GCLs. Geotext. Geomembr. 2001, 19, 427-444. [CrossRef]

2. Murray, H. Industrial clays case study. Min. Miner. Sustain. Dev. 2002, 64, 1-9.

3. Ece, Ö.I.; Güngör, N.; Alemdar, A. Influences of Electrolytes, Polymers and a Surfactant on Rheological Properties of Bentonite-Water Systems. J. Incl. Phenom. Macrocycl. Chem. 1999, 33, 155-168. [CrossRef]

4. Gleason, M.H.; Daniel, D.E.; Eykholt, G.R. Calcium and Sodium Bentonite for Hydraulic Containment Applications. J. Geotech. Geoenvironmental Eng. 1997, 123, 438-445. [CrossRef]

5. Mitchell, J.K.; Soga, K. Fundamentals of Soil Behavior; John Wiley \& Sons: Hoboken, NJ, USA, 2005.

6. Terzaghi, K.; Peck, R.B.; Mesri, G. Soil Mechanics in Engineering Practice; John Wiley \& Sons: New York, NY, USA, 1996.

7. Van Olphen, H. Introduction to Clay Colloid Chemistry; John Wiley \& Sons: New York, NY, USA, 1977.

8. Du, M.; Liu, J.; Clode, P.L.; Leong, Y.-K. Microstructure and rheology of bentonite slurries containing multiple-charge phosphate-based additives. Appl. Clay Sci. 2019, 169, 120-128. [CrossRef]

9. Goh, R.; Leong, Y.; Lehane, B. Bentonite slurries—zeta potential, yield stress, adsorbed additive and time-dependent behaviour. Rheol. Acta 2010, 50, 29-38. [CrossRef]

10. Yang, Y.; Du, Y.-J.; Reddy, K.; Fan, R. Effect of Phosphate Dispersant Amendment on Workability of Ca-Bentonite Slurry for Slurry Trench Cutoff-Wall Construction. Indian Geotech. J. 2017, 47, 445-452. [CrossRef]

11. Yildiz, N.; Sarikaya, Y.; Çalimli, A.; Çalımlı, A. The effect of the electrolyte concentration and $\mathrm{pH}$ on the rheological properties of the original and the Na2CO3-activated Kütahya bentonite. Appl. Clay Sci. 1999, 14, 319-327. [CrossRef]

12. Bonilla-Blancas, A.E.; Romero-Ibarra, I.; Vazquez-Arenas, J.G.; Sanchez-Solis, A.; Manero, O.; Alvarez-Ramirez, J. Molecular interactions arising in polyethylene-bentonite nanocomposites. J. Appl. Polym. Sci. 2018, 136. [CrossRef]

13. Axelsson, M.; Gustafson, G.; Fransson, A. Stop mechanism for cementitious grouts at different water-to-cement ratios. Tunn. Undergr. Space Technol. 2009, 24, 390-397. [CrossRef]

14. Liu, J.; Neretnieks, I. Physical and Chemical Stability of the Bentonite Buffer; Royal Institute of Technology: Stockholm, Sweden, 2006.

15. Yoon, J.; El Mohtar, C. Evaluation of Time-Dependent Yield Stress Using Dynamic Rheological Property of Bentonite Suspensions. Geotech. Test. J. 2013, 37, 20130075. [CrossRef]

16. Bingham, E.C. Fluidity and Plasticity; McGraw-Hill: New York, NY, USA, 1922.

17. Alther, G.R. The effect of the exchangeable cations on the physico-chemical properties of Wyoming bentonites. Appl. Clay Sci. 1986, 1, 273-284. [CrossRef]

18. Brandenburg, U.; Lagaly, G. Rheological properties of sodium montmorillonite dispersions. Appl. Clay Sci. 1988, 3, 263-279. [CrossRef]

19. Chen, J.S. Rheological Behavior of Na-Montmorillonite Suspensions at Low Electrolyte Concentration. Clays Clay Miner. 1990, 38, 57-62. [CrossRef]

20. Lagaly, G. Principles of flow of kaolin and bentonite dispersions. Appl. Clay Sci. 1989, 4, 105-123. [CrossRef]

21. Güngör, N.; Ece, Ö. Isik Effect of the adsorption of non-ionic polymer poly(vinyl)pyrolidone on the rheological properties of Na-activated bentonite. Mater. Lett. 1999, 39, 1-5. [CrossRef]

22. Güngör, N.; Karaoğlan, S. Interactions of polyacrylamide polymer with bentonite in aqueous systems. Mater. Lett. 2001, 48, 168-175. [CrossRef]

23. Işçi, S.; Ünlü, C.H.; Atıcı, O.G.; Güngör, N. Rheology and structure of aqueous bentonite-polyvinyl alcohol dispersions. Bull. Mater. Sci. 2006, 29, 449-456. [CrossRef] 
24. Theng, B.K.G. Formation and Properties of Clay-Polymer Complexes; Elsevier: Amsterdam, The Netherlands, 2012.

25. ASTM-D854. Standard Test Methods for Specific Gravity of Soil Solids by Water Pycnometer; ASTM International: West Conshohocken, PA, USA, 2010.

26. ASTM-D4318. Standard Test Methods for Liquid Limit, Plastic Limit, and Plasticity Index of Soils; ASTM International: West Conshohocken, PA, USA, 2010.

27. BS-1377. Methods of Test for Soils for Civil Engineering Purposes; British Standards Institution: London, UK, 1990.

28. ASTM-D2487. Standard Practice for Classification of Soils for Engineering Purposes (Unified Soil Classification System); ASTM International: West Conshohocken, PA, USA, 2011.

29. Santamarina, J.C.; Klein, K.A.; Wang, Y.; Prencke, E. Specific surface: Determination and relevance. Can. Geotech. J. 2002, 39, 233-241. [CrossRef]

30. Chapman, H. Cation-exchange capacity. In Methods of Soil Analysis (Number 9 in the Series Agronomy), Part 2; Black, A., Ed.; American Institute of Agronomy: Madison, WI, USA, 1965; pp. 891-901.

31. Besra, L.; Sengupta, D.; Roy, S.; Ay, P. Influence of polymer adsorption and conformation on flocculation and dewatering of kaolin suspension. Sep. Purif. Technol. 2004, 37, 231-246. [CrossRef]

32. Ruiz-Hitzky, E.; Van Meerbeek, A. Chapter 10.3 Clay Mineral- and Organoclay-Polymer Nanocomposite. In Developments in Clay Science; Elsevier BV: Amsterdam, The Netherlands, 2006; Volume 1, pp. 583-621.

33. Barvenik, F.W. Polyacrylamide Characteristics Related to Soil Applications. Soil Sci. 1994, 158, $235-243$. [CrossRef]

34. Kim, S.; Palomino, A.M. Factors influencing the synthesis of tunable clay-polymer nanocomposites using bentonite and polyacrylamide. Appl. Clay Sci. 2011, 51, 491-498. [CrossRef]

35. ASTM-D5890. Standard Test Method for Swell Index of Clay Mineral Component of Geosynthetic Clay Liners; ASTM International: West Conshohocken, PA, USA, 2011.

36. Alderman, N.; Meeten, G.; Sherwood, J. Vane rheometry of bentonite gels. J. Non-Newton. Fluid Mech. 1991, 39, 291-310. [CrossRef]

37. Dzuy, N.Q. Yield Stress Measurement for Concentrated Suspensions. J. Rheol. 1983, 27, 321-349. [CrossRef]

38. Liddel, P.V.; Boger, D.V. Yield stress measurements with the vane. J. Non-Newton. Fluid Mech. 1996, 63, 235-261. [CrossRef]

39. Yoon, J.; El Mohtar, C. Disturbance Effect on Time-Dependent Yield Stress Measurement of Bentonite Suspensions. Geotech. Test. J. 2012, 36, 20120082. [CrossRef]

40. Halder, B.K.; Palomino, A.M.; Reddy, K.; Yesiller, N.; Zekkos, D.; Farid, A.; De, A. The Shear Strength of “Tunable" Clay-Polymer Composite under Various Ionic Concentrations. Geo-Chicago 2016 2016, 61-72. [CrossRef]

41. Kim, S.; Palomino, A.M. Polyacrylamide-treated kaolin: A fabric study. Appl. Clay Sci. 2009, 45, $270-279$. [CrossRef]

42. Mpofu, P.; Addai-Mensah, J.; Ralston, J. Investigation of the effect of polymer structure type on flocculation, rheology and dewatering behaviour of kaolinite dispersions. Int. J. Miner. Process. 2003, 71, 247-268. [CrossRef]

43. Locat, J.; Demers, D. Viscosity, yield stress, remolded strength, and liquidity index relationships for sensitive clays. Can. Geotech. J. 1988, 25, 799-806. [CrossRef]

44. Perrot, A.; Rangeard, D.; Levigneur, A. Linking rheological and geotechnical properties of kaolinite materials for earthen construction. Mater. Struct. 2016, 49, 4647-4655. [CrossRef]

45. Kelessidis, V.; Maglione, R. Yield stress of water-bentonite dispersions. Colloids Surf. A Physicochem. Eng. Asp. 2008, 318, 217-226. [CrossRef]

46. Kang, X.; Cao, J.; Bate, B. Large-Strain Strength of Polymer-Modified Kaolinite and Fly Ash-Kaolinite Mixtures. J. Geotech. Geoenvironmental Eng. 2019, 145, 04018106. [CrossRef]

47. Spagnoli, G.; Rubinos, D.; Stanjek, H.; Fernandez-Steeger, T.; Feinendegen, M.; Azzam, R. Undrained shear strength of clays as modified by $\mathrm{pH}$ variations. Bull. Int. Assoc. Eng. Geol. 2011, 71, 135-148. [CrossRef]

(C) 2020 by the authors. Licensee MDPI, Basel, Switzerland. This article is an open access article distributed under the terms and conditions of the Creative Commons Attribution (CC BY) license (http://creativecommons.org/licenses/by/4.0/). 